\title{
A Phenome-Wide Association Study of genes associated with COVID-19 severity reveals shared genetics with complex diseases in the Million Veteran Program
}

Anurag Verma, $\mathrm{PhD}^{1,9 \pi}$; Noah Tsao, $\mathrm{BS}^{1,11 \pi}$; Lauren Thomann, $\mathrm{MPH}^{2}$; Yuk-Lam $\mathrm{Ho}^{7}$; Sudha Iyengar, $\mathrm{PhD}^{4,22}$, Shiuh-Wen Luoh, MD ${ }^{3,24}$, Rotonya Carr, $\mathrm{MD}^{1,10,43}$; Dana Crawford, $\mathrm{PhD}^{19,22,23}$; Jimmy T. Efird, $\mathrm{PhD}^{16}$; Jennifer Huffman, $\mathrm{PhD}^{2}$; Adriana Hung, $\mathrm{MD}^{17,20}$; Kerry Ivey, $\mathrm{PhD}^{9,21,22}$; Michael Levin, $\mathrm{MD}^{10}$, $\mathrm{PhD}^{3,24}$; Julie Lynch, $\mathrm{PhD}^{5}$; Pradeep Natarajan, MD, MMSc ${ }^{2,15,31,32}$; Saiju Pyarajan, $\mathrm{PhD}^{2,12}$; Alexander Bick MD, $\mathrm{PhD}^{2,28}$; Lauren Costa ${ }^{7}$; Giulio Genovese, $\mathrm{PhD}^{32,33,34}$; Richard Hauger, $\mathrm{MD}^{35}$; Ravi Madduri ${ }^{36,37}$; Gita Pathak $\mathrm{PhD}^{6,42}$, Renato Polimanti $\mathrm{PhD}^{6,42}$, Benjamin Voight, $\mathrm{PhD}^{1,9,26,27}$; Marijana Vujkovic, $\mathrm{PhD}^{1,10}$; Maryam Zekavat, BSc ${ }^{2,38,39}$; Hongyu Zhao, $\mathrm{PhD}^{6,39,40}$; Marylyn D Ritchie, $\mathrm{PhD}^{3} ;$ VA Million Veteran Program COVID-19 Science Initiative, Kyong-Mi Chang, $\mathrm{MD}^{1,10}$; Kelly Cho, $\mathrm{PhD}^{7}$; Juan P. Casas, MD, $\mathrm{PhD}^{7,13}$; Philip S. Tsao, $\mathrm{PhD}^{8,41}$; J. Michael Gaziano, MD, MPH ${ }^{7,13}$; Christopher O’Donnell, MD, MPH ${ }^{2,12,13}$; Scott Damrauer, MD ${ }^{1,11} *$, Katherine Liao, MD, MPH $^{2,12,13} *$

${ }^{1}$ Corporal Michael Crescenz VA Medical Center, Philadelphia, Philadelphia, USA

${ }^{2}$ VA Boston Healthcare System, Boston, Massachusetts, USA

${ }^{3}$ VA Portland Health Care System, Portland OR, USA

${ }^{4}$ Louis Stokes Cleveland VA Medical Center, Cleveland, OH, USA

${ }^{5}$ VA Informatics and Computing Infrastructure, VA Salt Lake City Health Care System, Salt Lake City, Utah, USA.

${ }^{6}$ VA Connecticut Healthcare System, West Haven, CT, USA

${ }^{7}$ Massachusetts Veterans Epidemiology Research and Information Center (MAVERIC), VA Boston Healthcare System, Boston, Massachusetts, USA

${ }^{8}$ VA Palo Alto Health Care System, Palo Alto, California, USA

${ }^{9}$ Department of Genetics, Perelman School of Medicine, University of Pennsylvania, Philadelphia, Pennsylvania, USA.

${ }^{10}$ Department of Medicine, Perelman School of Medicine, University of Pennsylvania, Philadelphia, Pennsylvania, USA

${ }^{11}$ Department of Surgery, Perelman School of Medicine, University of Pennsylvania, Philadelphia, Pennsylvania, USA

${ }^{12}$ Harvard Medical School, Boston, Massachusetts, USA.

${ }^{13}$ Brigham and Women's Hospital, Boston, Massachusetts, USA.

${ }^{14}$ Cardiovascular Research Center, Massachusetts General Hospital, Boston, Massachusetts, USA.

${ }^{15}$ Department of Medicine, Brigham and Women's Hospital, Harvard Medical School, Boston, Massachusetts, USA

${ }^{16}$ Cardiovascular Medicine Division, Department of Medicine, Brigham and Women's Hospital, Harvard Medical

School, Boston, Massachusetts, USA

${ }^{17}$ Division of Hematology and Medical Oncology, Knight Cancer Institute, Oregon Health and Science University, Portland, Oregon, USA

${ }^{18}$ College of Nursing and Health Sciences, University of Massachusetts, Lowell, Massachusetts, USA.

${ }^{19}$ Cleveland Institute for Computational Biology, Department of Population and Quantitative Health Sciences, Case Western Reserve University, Cleveland, Ohio, USA.

${ }^{20}$ Cooperative Studies Program Epidemiology Center, Health Services Research and Development, DVAHCS (Duke University Affiliate), Durham, North Carolina, USA.

${ }^{21}$ Tennessee Valley Healthcare System (Nashville VA) \& Vanderbilt University, Nashville, Tennessee, USA.

${ }^{22}$ Department of Population and Quantitative Health Sciences, Case Western Reserve University, Cleveland, Ohio, USA.

${ }^{23}$ Department of Genetics and Genome Sciences, Case Western Reserve University, Cleveland, Ohio, USA

${ }^{24}$ Division of Hematology and Medical Oncology, Knight Cancer Institute, Oregon Health and Science University, Portland, Oregon, USA

${ }^{25}$ Department of Genetics, Harvard Medical School, Boston, Massachusetts, USA.

${ }^{26}$ Department of Systems Pharmacology and Translational Therapeutics, Perelman School of Medicine, University of Pennsylvania, Philadelphia, Pennsylvania, USA

${ }^{27}$ Institute for Translational Medicine and Therapeutics, Perelman School of Medicine, University of Pennsylvania, Philadelphia, Pennsylvania, USA

${ }^{28}$ Vanderbilt University, Nashville, Tennessee, USA 
$55{ }^{29}$ South Australian Health and Medical Research Institute, Infection and Immunity Theme, South Australia,

56 Australia

$57{ }^{30}$ Harvard T.H. Chan School of Public Health, Department of Nutrition, Massachusetts, USA

$58 \quad{ }^{31}$ Cardiovascular Research Center, Massachusetts General Hospital, Boston, Massachusetts, USA.

$59{ }^{32}$ Program in Medical and Population Genetics and the Cardiovascular Disease Initiative, Broad Institute of Harvard

60 \& MIT, Cambridge, Massachusetts, USA

$61{ }^{33}$ Stanley Center for Psychiatric Research, Broad Institute of MIT and Harvard, Cambridge, MA, USA

$62 \quad{ }^{34}$ Department of Genetics, Harvard Medical School, Boston, MA, USA

$63{ }^{35}$ Department of Psychiatry, University of California, San Diego, La Jolla, CA; Center of Excellence for Stress and

64 Mental Health, VA San Diego Healthcare System, San Diego, CA, USA

$65{ }^{36}$ University of Chicago Consortium for Advanced Science and Engineering, The University of Chicago, Chicago,

66 Illinois, USA

$67{ }^{37}$ Data Science and Learning Division, Argonne National Laboratory, Lemont, Illinois.

$68{ }^{38}$ Broad Institute of MIT \& Harvard, Cambridge, MA, USA

$69{ }^{39}$ Yale School of Medicine New Haven, CT, USA

$70 \quad{ }^{40}$ Computational Biology and Bioinformatics Program, Yale University, New Haven, CT, USA

$71{ }^{41}$ Department of Medicine (Cardiovascular Medicine), Stanford University School of Medicine, Stanford, CA, USA

$72{ }^{42}$ Department of Psychiatry, Yale School of Medicine, Connecticut, USA

$73{ }^{43}$ University of Washington, Division of Gastroenterology

74 Seattle, WA USA

75

76

77

106 Anurag Verma: anurag.verma@pennmedicine.upenn.edu, Katherine Liao: kliao@ bwh.harvard.edu 
109 Abstract

111 The study aims to determine the shared genetic architecture between COVID-19 severity with

112 existing medical conditions using electronic health record (EHR) data. We conducted a

113 Phenome-Wide Association Study (PheWAS) of genetic variants associated with critical illness

$114(\mathrm{n}=35)$ or hospitalization $(\mathrm{n}=42)$ due to severe COVID-19 using genome-wide association

115 summary from the Host Genetics Initiative. PheWAS analysis was performed using genotype-

116 phenotype data from the Veterans Affairs Million Veteran Program (MVP). Phenotypes were

117 defined by International Classification of Diseases (ICD) codes mapped to clinically relevant

118 groups using published PheWAS methods. Among 658,582 Veterans, variants associated with

119 severe COVID-19 were tested for association across 1,559 phenotypes. Variants at

120 the $A B O$ locus (rs495828, rs505922) associated with the largest number of phenotypes $\left(\mathrm{n}_{\mathrm{rs} 495828}=\right.$

12153 and $\left.\mathrm{n}_{\mathrm{rs} 505922}=59\right)$; strongest association with venous embolism, odds ratio $\left(\mathrm{OR}_{\mathrm{rs} 495828} 1.33\right.$

$122\left(\mathrm{p}=1.32 \times 10^{-199}\right)$, and thrombosis $\mathrm{OR}_{\mathrm{r} 5505922} 1.33, \mathrm{p}=2.2 \times 10^{-265}$. Among 67 respiratory conditions

123 tested, 11 had significant associations including $M U C 5 B$ locus (rs35705950) with increased risk

124 of idiopathic fibrosing alveolitis OR 2.83, $\mathrm{p}=4.12 \times 10^{-191}$; CRHRI (rs61667602) associated with

125 reduced risk of pulmonary fibrosis, OR $0.84, \mathrm{p}=2.26 \times 10^{-12}$. The TYK2 locus (rs11085727)

126 associated with reduced risk for autoimmune conditions, e.g., psoriasis OR $0.88, \mathrm{p}=6.48 \times 10^{-23}$,

127 lupus OR $0.84, \mathrm{p}=3.97 \times 10^{-06}$. PheWAS stratified by genetic ancestry demonstrated differences

128 in genotype-phenotype associations across ancestry. LMNA (rs581342) associated with

129 neutropenia OR $1.29 \mathrm{p}=4.1 \times 10^{-13}$ among Veterans of African ancestry but not European.

130 Overall, we observed a shared genetic architecture between COVID-19 severity and conditions

131 related to underlying risk factors for severe and poor COVID-19 outcomes. Differing 
medRxiv preprint doi: https://doi.org/10.1101/2021.05.18.21257396; this version posted October 15, 2021. The copyright holder for this preprint (which was not certified by peer review) is the author/funder, who has granted medRxiv a license to display the preprint in perpetuity.

It is made available under a CC-BY 4.0 International license .

132 associations between genotype-phenotype across ancestries may inform heterogenous outcomes

133 observed with COVID-19. Divergent associations between risk for severe COVID-19 with

134 autoimmune inflammatory conditions both respiratory and non-respiratory highlights the shared

135 pathways and fine balance of immune host response and autoimmunity and caution required

136 when considering treatment targets. 
medRxiv preprint doi: https://doi.org/10.1101/2021.05.18.21257396; this version posted October 15, 2021. The copyright holder for this preprint (which was not certified by peer review) is the author/funder, who has granted medRxiv a license to display the preprint in perpetuity.

It is made available under a CC-BY 4.0 International license.

\section{Introduction}

139 Coronavirus disease 2019 (COVID-19) first identified in December of $2019^{1}$, became a global

140 pandemic by March 2020. As of September 2021, COVID-19, transmitted by the SARS-CoV-2

141 virus, has resulted in the loss of over 4.6 million lives worldwide. ${ }^{2}$ Identifying host genetic

142 variants associated with severe clinical manifestations from COVID-19, can identify key

143 pathways important in the pathogenesis of this condition. International efforts such as the

144 COVID-19 Host Genetics Initiative (HGI) ${ }^{3}$ have meta-analyzed genome-wide association study

145 (GWAS) summary statistics at regular intervals to identify novel genetic associations with

146 COVID-19 severity. Thus far, ten independent variants associated with COVID-19 severity at

147 genome-wide significance have been identified, most notably at the $A B O$ locus. ${ }^{4}$ These GWASs

148 have also identified variations in genes involving inflammatory cytokines and interferon

149 signaling pathways such as IFNAR2, TYK2, and DPP9. ${ }^{4}$

150 The unprecedented availability of genome-wide data for COVID-19 provides an

151 opportunity to study clinical conditions that share genetic risk factors for COVID-19 severity.

152 Examining known conditions, each with a body of knowledge regarding important pathways and

153 targets, may in turn improve our understanding of pathways relevant for COVID-19 severity and

154 inform the development of novel treatments against this pathogen. The Phenome-Wide

155 Association Study (PheWAS) is an approach for simultaneously testing genetic variants'

156 association with a wide spectrum of conditions and phenotypes. ${ }^{5}$ The Veteran's Affairs (VA)

157 Million Veterans Program (MVP) has generated genotypic data on over 650,000 participants

158 linked with electronic health record (EHR) data containing rich phenotypic data, enables large-

159 scale PheWAS. Moreover, MVP has the highest racial and ethnic diversity of the major biobanks 
medRxiv preprint doi: https://doi.org/10.1101/2021.05.18.21257396; this version posted October 15, 2021. The copyright holder for this preprint (which was not certified by peer review) is the author/funder, who has granted medRxiv a license to display the preprint in perpetuity.

It is made available under a CC-BY 4.0 International license.

160 worldwide affording an opportunity to compare whether associations are similar across genetic

161 ancestries. $^{6}$

The objective of this study was to use existing clinical EHR data to identify conditions

163 that share genetic variants with COVID-19 severity using the disease-agnostic PheWAS

164 approach. Since COVID-19 is a new condition, identifying existing conditions which share

165 genetic susceptibility may allow us to leverage existing knowledge from these known conditions

166 to provide context regarding important pathways for COVID-19 severity, as well as how

167 pathways may differ across subpopulations.

\section{Methods}

\section{Data sources}

170 The VA MVP is a national cohort launched in 2011 designed to study the contributions of

171 genetics, lifestyle, and military exposures to health and disease among US Veterans. ${ }^{6}$

172 Blood biospecimens were collected for DNA isolation and genotyping, and the biorepository was

173 linked with the VA EHR, which includes diagnosis codes (International Classification of

174 Diseases ninth revision [ICD-9] and tenth revision [ICD-10]) for all Veterans followed in the

175 healthcare system up to September 2019. The single nucleotide polymorphism (SNP) data in the

176 MVP cohort was generated using a custom Thermo Fisher Axiom genotyping platform called

177 MVP 1.0. The quality control steps and genotyping imputation using 1000 Genomes

178 cosmopolitan reference panel on the MVP cohort has been described previously. ${ }^{7}$ All individuals

179 in the study provided written informed consent as part of the MVP. This study was approved

180 through the Veterans Affairs central institutional review board as part of the MVP. 
medRxiv preprint doi: https://doi.org/10.1101/2021.05.18.21257396; this version posted October 15, 2021. The copyright holder for this preprint (which was not certified by peer review) is the author/funder, who has granted medRxiv a license to display the preprint in perpetuity.

It is made available under a CC-BY 4.0 International license .

\section{Genetic variant selection}

182 An overview of the analytic workflow is outlined in Fig 1. Variants were derived from the

183 COVID-19 HGI GWAS meta-analysis release $v 6^{3}$. In this study, we analyzed the following HGI

184 GWAS summary statistics: 1) hospitalized and critically ill COVID-19 vs. population controls

185 denoted as "A2" in HGI, and referred to as "critical COVID" in this study, and 2) hospitalized

186 because of COVID-19 vs. population controls, denoted as "B2" in HGI, referred to as

187 "hospitalized COVID" in this study ${ }^{3}$. For each GWAS, variants with a Benjamini-Hochberg false

188 discovery rate (FDR) corrected p-value $<0.01$ were selected as candidate lead SNPs $(3,502$

189 associated with critical COVID, and 4,336 associated with hospitalized COVID). Variants with

$190 \quad \mathrm{r}^{2}<0.1$ were clustered within a $250 \mathrm{~kb}$ region according to 1000 Genomes phase 3 transethnic

191 reference panel ${ }^{8}$, resulting in 45 independent variants associated with critical COVID and 42

192 variants associated with hospitalized COVID summary statistics. The lead variants from each set

193 of GWAS summary statistics are available in eTable 1.

\section{Outcomes}

195 For both MVP, clinical data prior to the onset of the COVID-19 pandemic were used to reduce

196 potential confounding bias from SARS-CoV-2 infection on existing conditions. Phenotypes

197 were defined by phecodes from prior studies ${ }^{5,9}$. Each phecode represents ICD codes grouped into

198 clinically relevant phenotypes for clinical studies. For example, the phecode "deep venous

199 thrombosis" includes "venous embolism of deep vessels of the distal lower extremities," and

200 “deep venous thrombosis of the proximal lower extremity," both of which have distinct ICD

201 codes. Using this approach, all ICD codes for all Veterans in MVP were extracted and each 
202 assigned a phenotype defined by a phecode. ICD-9 and ICD-10 codes were mapped to 1876

203 phecodes, as previously described. ${ }^{5,9}$

204 For each phecode, participants with $\geq 2$ phecode-mapped ICD-9 or ICD-10 codes were defined as 205 cases, whereas those with no instance of a phecode-mapped ICD-9 or ICD-10 code were defined

206 as controls. Based on our previous simulation studies of ICD EHR data, populations where the

207 phecode comprises $<200$ cases were more likely to result in spurious results ${ }^{10}$, and we thus

208 applied this threshold in each ancestry group. In total, we analyzed 1,617 (EUR), 1304 (AFR),

209993 (HIS), 294 (ASN) phecodes from the MVP cohort.

\section{Phenome-wide association studies}

211 The primary PheWAS analysis used SNPs identified from the HGI GWAS of critical and

212 hospitalized COVID, and tested association of these SNPs with phenotypes extracted from the

213 EHR using data prior to the COVID-19 pandemic. Logistic regression using PLINK2 to

214 examine the SNP association with phecodes and firth regression was applied when logistic

215 regression model failed to converge. Regression models were adjusted for sex, age (at

216 enrollment), age squared, and the first 20 principal components. Genetic ancestry was determined

217 using the HARE method for four major groups: African (AFR), Asian (ASN), Hispanic (HIS),

218 and European (EUR) ancestry ${ }^{11}$. Ancestry-specific PheWAS was first performed in these four

219 groups, and summary data were meta-analyzed using an inverse-variance weighted fixed-effects

220 model implemented in the PheWAS R package ${ }^{9}$. We assessed heterogeneity using $\mathrm{I}^{2}$ and

221 excluded any results with excess heterogeneity $\left(\mathrm{I}^{2}>40 \%\right)$. 
medRxiv preprint doi: https://doi.org/10.1101/2021.05.18.21257396; this version posted October 15, 2021. The copyright holder for this preprint (which was not certified by peer review) is the author/funder, who has granted medRxiv a license to display the preprint in perpetuity.

It is made available under a CC-BY 4.0 International license .

222 To address multiple testing, an association between SNP and phecode with FDR $\mathrm{p}<0.01$ was

223 considered significant. Thus, the threshold for significance was $\mathrm{p}<6.07 \times 10^{-05}$ for critical

224 COVID lead variants, and $\mathrm{p}<4.13 \times 10^{-05}$ for hospitalized COVID lead variants. In the main

225 manuscript we highlight PheWAS significant associations using FDR $<0.01$ and an effect size

226 associated with increased or reduced risk for a condition by $10 \%$, with complete PheWAS results

227 provided in S2 Table and S3 Table.

\section{Results}

229 We studied 658,582 MVP participants, with mean age 68 years (SD), 90\% male, with $30 \%$

230 participants from non-European ancestry (Table 1). The PheWAS was performed on 35 genetic

231 variants associated with critical COVID-19, and 42 genetic variants (S1 Table) associated with

232 hospitalized COVID, across 1,559 phenotypes.

233 From the trans-ethnic meta-analysis, we identified 151 phenotypes significantly associated with

234 critical COVID GWAS-identified variants, and 156 associations with hospitalized COVID

235 GWAS-identified lead variants (FDR, p<0.01). Among these lead variants with significant

236 PheWAS associations, 10 SNPs were associated with reduced risk of critical and hospitalized

237 COVID-19 in HGI. Six variants were common to both severe and hospitalized COVID and had

238 significant PheWAS associations, namely, variations nearest to the genes $A B O$ (rs495828 and

239 rs505922), DPP9 (rs2277732), MUC5B (rs35705950), TYK2 (rs11085727), and CCHCR1

240 (rs9501257) (S2 Table and S3 Table). 
medRxiv preprint doi: https://doi.org/10.1101/2021.05.18.21257396; this version posted October 15, 2021. The copyright holder for this preprint (which was not certified by peer review) is the author/funder, who has granted medRxiv a license to display the preprint in perpetuity.

It is made available under a CC-BY 4.0 International license .

243 Association of ABO loci with known risk factors and outcomes related to COVID-19 severity

244 In the transethnic meta-analysis, the phenotypes with the strongest association with variants near

$245 A B O$ locus (rs495828 and rs505922) was "hypercoagulable state" $\left(\mathrm{OR}_{\text {critical_Phew }}=1.48\right.$ [1.42 -

$2461.54], P_{\text {critical_PheWAS }}=1.84 \times 10^{-40} ; \mathrm{OR}_{\text {hospitalized_PheWAS }}=1.51[1.46-1.56], P_{\text {hospitalized_PheWAS }}=$

$2472.11 \times 10^{-55}$, Fig 2). The ABO loci had the largest number of significant PheWAS association

248 findings, accounting for 35\% (53/151) of significant phenotype associations in the critical

249 COVID PheWAS, and 37\% (59/156) in the hospitalized COVID PheWAS. The phenotypes with

250 the most significant associations and largest effect size were related to hypercoagulable states

251 and coagulopathies. As expected, conditions not related to coagulopathy associated with the

$252 A B O$ locus, included type 2 diabetes and ischemic heart disease, have been reported as risk

253 factors for or are complications associated with COVID-19 severity and mortality (Fig 2, S2

254 Table and S3 Table).

255 Associations between variants associated with COVID-19 severity and respiratory conditions

256 and infections

257 Among 68 respiratory conditions, only 11 diseases had significant associations (FDR $<0.01$ )

258 shared with genetic variants associated with severe COVID-19. The most significant association

259 was observed between rs35705950 $(M U C 5 B)$ and idiopathic fibrosing alveolitis $(\mathrm{OR}=2.83$

$260[2.76-2.90] ; P=4.12 \times 10^{-191}$ ), also known as idiopathic pulmonary fibrosis (IPF). Similarly,

261 rs2277732 near DPP9 was associated with IPF (OR $\left.=1.16[1.09-1.22] ; P=5.84 \times 10^{-06}\right)$, both

262 association between $M U C 5 B, D P P 9$ variants and IPF has been reported in previous studies. ${ }^{12}$

263 However, the association of genetic variants with other respiratory conditions may represent

264 novel findings: the association of intronic variant rs61667602 in CRHR1 with reduced risk of 
265 post inflammatory pulmonary fibrosis $\left(\mathrm{OR}=0.84[0.80-0.89] ; P=2.26 \times 10^{-12}\right)$, "alveolar and

266 parietoalveolar pneumonopathy" $\left(\mathrm{OR}=0.80[0.72-0.88] ; P=1.58 \times 10^{-08}\right)$ and $\mathrm{IPF}(\mathrm{OR}=0.87$

$\left.267[0.82-0.92], P=7.5 \times 10^{-07}\right)$. We did not detect associations between any of the variants and

268 other respiratory conditions which are known risk factors for COVID-19 such as COPD, cystic

269 fibrosis, pulmonary hypertension. (S2 Table, S3 Table).

270 Associations between variants associated with COVID-19 severity and reduced risk for certain

271 phenotypes

272 The rs 11085727-T allele of $T Y K 2$, a lead variant from the both critically ill and hospitalized

273 COVID GWAS was associated with a reduced risk for psoriasis $(\mathrm{OR}=0.88[0.86-0.91], P=$

$\left.6.48 \times 10^{-23}\right)$, psoriatic arthropathy $\left(\mathrm{OR}=0.82[0.76-0.87], P=6.97 \times 10^{-12}\right)$, and lupus $(\mathrm{OR}=$

$\left.2750.84[0.76-0.91], P=63.97 \times 10^{-06}\right)$. This TYK2 signal has been previously reported to be

276 associated with reduced risk of psoriasis, psoriatic arthropathy, type 1 diabetes, systemic lupus

277 erythematosus and RA as well as other autoimmune inflammatory conditions ${ }^{13,14}$ (Table 2).

278 Ancestry specific PheWAS provide insights into disease risks across ancestries

279 The PheWAS analyses performed across four major genetic ancestry group in MVP observed

280 similar findings as the overall meta-analysis with few associations unique to each ancestry. (Fig

2813 3, S8 Table). SNP rs581342 (LMNA), associated with severe COVID-19, was a highly prevalent

282 variant among subjects with AFR ancestry $(\mathrm{MAF}=0.53)$ and was associated with neutropenia

$283\left(\mathrm{OR}_{\mathrm{AFR}}=0.82[0.76-0.87], P_{A F R}=4.09 \times 10^{-13}\right)$; this association was not observed in larger

284 population of EUR descent (S8 Table). Following up on this finding, we extracted data on

285 laboratory values and observed a strong association between $L M N A$ with lower white blood cell 
286 count $\left(\right.$ beta $\left.=-0.34[-0.35,-0.32], P_{\mathrm{AFR}}=1 \times 10^{-300}\right)$ and lower median neutrophil fraction $($ beta $=$

$\left.287-1.84[-1.94,-1.75], P_{\mathrm{AFR}}=1 \times 10^{-300}\right)$ compared to those without this variant. This association in

288 laboratory values was again more significant with a stronger effect size among subjects with

289 AFR ancestry in comparison to EUR ( $\mathrm{P}=0.005)$. Among AFR individuals, each allele was

290 associated with a $1.84 \%$ lower neutrophil fraction, where among EUR individuals, each allele

291 was associated with only a $0.04 \%$ reduction (S9 Table).

292 Similarly, associations between rs9268576 (HL-DRA) and thyrotoxicosis was only observed in

293 AFR ancestry participants. The EUR ancestry specific PheWAS identified 39 significant

294 associations which were not observed in other ancestry groups. One such association was

295 between MUC5B variant and phecode for “dependence on respirator [Ventilator] or

296 supplemental oxygen" $\left(\mathrm{OR}_{\mathrm{EUR}}=1.16[1.11-1.12], P_{\text {EUR }}=1.72 \times 10^{-10}\right)$ among EUR ancestry

297 participants was not significant in other ancestry population (S8 Table). It is important to note

298 that the conditions with significant association among EUR participants had similar prevalence

299 among other ancestries. However, since there were overall fewer subjects in non-EUR ancestry

300 groups, this likely resulted in lower statistical power to detect associations. All ancestry specific

301 PheWAS results are available in supplementary tables (S4 Table, S5 Table, S6 Table, S7 Table).

$\underline{\text { Association with variation at sex chromosome }}$

304 In the hospitalized COVID-19 GWAS, we identified rs4830964 as the only lead variant on

305 chromosome X. The SNP is located near ACE2 and was associated "non-healing surgical

306 wound" $\left(\mathrm{OR}=0.92[0.89-0.96], P=2.23 \times 10^{-05}\right)$. Notably, the SNP had nominal association

$307(\mathrm{p}<0.05)$ with type 2 diabetes and diabetes related complications that are previously reported 
medRxiv preprint doi: https://doi.org/10.1101/2021.05.18.21257396; this version posted October 15, 2021. The copyright holder for this preprint (which was not certified by peer review) is the author/funder, who has granted medRxiv a license to display the preprint in perpetuity.

It is made available under a CC-BY 4.0 International license .

association with variation in ACE2 (S3 Table). We did not observe any association with this

309 variant in the ancestry specific PheWAS analysis.

\section{Discussion}

311 In this large-scale PheWAS, we identified the shared genetic architecture between variants

312 associated with severe COVID-19 and other complex conditions using data from MVP, one of

313 the largest and most diverse biobanks in the world. Broadly, these risk alleles identified

314 conditions associated with risk factors for severe COVID-19 manifestations such as T2D,

315 ischemic heart disease across all ancestries. Notably, the strongest associations with the highest

316 effect size were related to coagulopathies, specifically, hypercoagulable state including deep

317 venous thrombosis and other thrombotic complications, also shared variants associated with

318 severe COVID-19. In contrast, among respiratory conditions, only idiopathic pulmonary fibrosis

319 and chronic alveolar lung disease shared genetic risk factors, with the notable absence of an

320 association with COPD, pulmonary hypertension, and other respiratory infections. When

321 comparing findings from the two largest ancestry groups in MVP, AFR and EUR, we observed

322 that a risk allele associated with severe COVID-19 that shares an association with neutropenia

323 on among Veterans of AFR ancestry. Finally, we observed that variants associated with severe

324 COVID-19 had an opposite association, or reduced odds with autoimmune inflammatory

325 conditions, such as psoriasis, psoriatic arthritis, RA, and inflammatory lung conditions.

326 A classic GWAS tests the association between millions of genetic variants with the presence or

327 absence of one phenotype, e.g., GWAS of deep venous thrombosis. In the COVID-19 HGI

328 GWAS, the "phenotype" was patients hospitalized for or critically ill from COVID-19.

329 Clinically, this population includes a mixture of patients with a complex list of medical 
conditions at high risk for severe COVID complications and those who had actual complications

331 from COVID-19. Thus, we would anticipate that many of the significant phenotypes would be

332 associated with risk factors such as obesity and deep venous thrombosis. The clinical data used

333 in this study pre-dates the emergence of COVID-19 to reduce potential confounding bias that can

334 occur in a population infected with SARS-CoV-2, e.g., interaction between COVID-19 and type

3352 diabetes. Additionally, our findings suggest that the PheWAS approach can be a useful tool to

336 identify clinical factors related to emerging infectious diseases regarding severity or

337 complications when genomic data are available.

339 The PheWAS results of SNPs in the $A B O$ locus served as a positive control for this study.

340 Genetic variations in $A B O$ are an established risk factor for COVID-19 severity. Patients with

341 blood group A have a higher risk of requiring mechanical ventilation and extended ICU stay

342 compared with patients with blood group O. ${ }^{15}$ These same variations at $A B O$ had known

343 associations with a spectrum of blood coagulation disorders identified in studies pre-dating

344 COVID-19. ${ }^{16-18}$ The PheWAS of ABO variants identified associations with increased risk of

345 deep vein thrombosis, pulmonary embolism, and other circulatory disorders, in line with prior

346 studies, and recent studies among patients hospitalized with COVID-19. ${ }^{19-23}$

348 Among the respiratory conditions, only idiopathic pulmonary fibrosis (IPF) and chronic alveoli

349 lung disease had associations with the variants near genes MUC5B, CRHR1, and NSF. Located

350 in the enhancer region of the $M U C 5 B$, rs35705950, is a known risk factor for IPF, and a high

351 mortality rate was observed among the COVID-19 patients with pre-existing

$352 \mathrm{IPF}^{24}$ However, the variant is associated with a reduced risk of severe COVID-19 (OR=0.89),

353 revealing the risk allele's opposing effect for infection and pulmonary fibrosis. In a separate 
study of MVP participants tested for COVID-19, we identified a significant mediating effect of

355 the $M U C 5 B$ variant in reducing risk for pneumonia due to COVID- $19^{25}$. An intronic variation in

356 CRHR1 (rs61667602-T) had reduced risk for severe COVID-19 (OR=0.91) as well as

357 respiratory conditions such as IPF. CRHRl gene is a receptor that binds to the corticotropin-

358 releasing hormone has a key role in immune, behavioral, autonomic, and neuroendocrine

359 responses to stress. Depression and anxiety are the known conditions associated with variations

360 in $C R H R 1$, but variations in this gene have also shown associations enhanced improvement in

361 pulmonary function in asthma patients taking inhaled corticosteroid ${ }^{26}$. This finding may inform

362 results from the RECOVERY clinical trial of patients hospitalized with COVID-19 where a

363 survival benefit was observed for dexamethasone use among those receiving respiratory

364 support $^{27}$.

366 Several conditions shared genetic variants associated with severe COVID-19, however, the

367 association was for reduced odds for these conditions. All except one, rosacea, have a known

368 autoimmune etiology. The existing literature can help explain the dual association between

369 reduced risk of autoimmune conditions such as psoriasis and RA and increased risk of severe

370 COVID-19 via TYK2. TYK2, a member of the Janus Kinase (JAK) family of genes, plays a key

371 role in cytokine signal transduction and the inflammatory response, particularly via IL-12, IL-23,

372 and is also important for IL-6 and IL-10 signaling (Fig 3). ${ }^{28}$ TYK2 serves a central role in type 1

373 interferon signaling, part of the innate immune response blocking the spread of a virus from

374 infected to uninfected cells. Partial loss of $T Y K 2$ function is associated with reduced risk for

375 several autoimmune disorders such as RA and psoriatic disease, conditions treated with

376 immunosuppressive therapy. ${ }^{13,29-32}$ Humans with complete TYK2 loss of function have clinically

377 significant immunodeficiency with increased susceptibility to mycobacterial and viral 
378 infections. $^{28,33}$ In line with the TYK2 findings is enhanced steroid responsiveness among patients

379 with asthma carrying the $C R H R 1$ variant $^{34}$. Here again, a variant associated with severe COVID-

38019 is associated with a non-COVID phenotype responsive to immunosuppressive therapy. In

381 summary, reviewing the overall signal of opposing associations of variants with COVID-19 and

382 autoimmune conditions, highlights the known fine balance between host immune response and

383 autoimmunity.

385 While non-white populations are disproportionately affected by COVID-19, the current genetic

386 studies of severe COVID-19 still predominantly consist of individuals from EUR ancestry. MVP

387 has the most racial and ethnic diversity compared to other major biobanks. The availability of

388 linked EHR data provide the opportunity to provide more in-depth studies of genotype-

389 phenotype associations observed from the PheWAS. The GWAS from the HGI provides the

390 most diverse genomic data of COVID-19 consisting of participants from over 25 countries EUR

391 (33\% non-EUR samples), enabling identification of variants more prevalent in non-EUR

392 populations. In the present study, we observed that a variant located in the LMNA gene locus was

393 associated with neutropenia in AFR ancestry but not in other ancestry groups, including EUR

394 which would have been well powered to detect an association. Furthermore, examination of

395 actual neutrophil percentages measured as part of routine care demonstrated stronger

396 associations in Veterans of AFR ancestry compared to EUR.

398 LMNA variants are associated with a broad spectrum of cardiomyopathies such as dilated

399 cardiomyopathies, familial atrial fibrillation. However, the association with neutropenia has not

400 been previously reported. Neutropenia refers to an abnormally low number of neutrophils cell in

401 the blood, and predisposes to increased risk of infection . Epidemiology studies have shown that 
402 lower neutrophil counts are more common in individuals with African Ancestry ${ }^{36}$ and are

403 hypothesized to be a result of selection and generally considered benign. Whether low

404 neutrophil levels may clinically impact COVID-19 outcomes remains to be seen and should be

405 further studied.

407 Limitations

408 We note several limitations. First, the PheWAS was designed as a broad screen to test for

409 potentially clinically relevant associations between genes and phenotypes, with limited power to

410 detect associations among uncommon conditions, and when further stratified by genetic ancestry.

411 Findings from this study suggest that variants associated with severe COVID-19 are also

412 associated with reduced odds of having an autoimmune inflammatory condition. However, the

413 results cannot provide information on the impact of actual SARS-CoV-2 infection in these

414 individuals after diagnosis of an autoimmune disease

\section{Conclusions}

417 The PheWAS of genetic variants reported to associate with severe COVID-19 demonstrated 418 shared genetic architecture between COVID-19 severity and known underlying risk factors for 419 both severe COVID-19 and poor COVID-19 outcomes, rather than susceptibility to other viral

420 infections. Overall, the associations observed were generally consistent across genetic ancestries,

421 with the exception of a stronger association with neutropenia among Veterans of African

422 ancestry than European ancestry. Notably, only few respiratory conditions had a shared genetic

423 association with severe COVID-19. Among these, variants associated with a reduced risk for

424 severe COVID-19 had an opposite association, with reduced risk for inflammatory and fibrotic

425 pulmonary conditions. Similarly, other divergent associations were observed between severe 
426 COVID-19 and autoimmune inflammatory conditions, shedding light on the concept of the fine

427 balance between immune tolerance and immunodeficiency. This balance will be important when

428 considering therapeutic targets for COVID-19 therapies where pathways may control both

429 inflammation and the viral host response.

\section{$431 \quad$ Funding}

432 This research is based on data from the Million Veteran Program, Office of Research and

433 Development, Veterans Health Administration, and was supported by award MVP035. This

434 publication does not represent the views of the Department of Veteran Affairs or the United

435 States Government. R.M.C. is supported by NIH grants R01 AA026302 and P30 DK0503060.

436 K.P.L. is supported by NIH P30 AR072577, and the Harold and Duval Bowen Fund.

\section{Conflict of Interest}

438 RMC has received research support from Intercept Pharmaceuticals, Inc and Merck \& Co. MDR

439 is on the scientific advisory board for Goldfinch Bio and Cipherome. CJO is an employee of

440 Novartis Institute for Biomedical Research. PN reports grant support from Amgen, Apple,

441 AstraZeneca, Boston Scientific, and Novartis, personal fees from Apple, AstraZeneca,

442 Blackstone Life Sciences, Genentech, and Novartis, and spousal employment at Vertex, all

443 unrelated to the present work.

\section{Acknowledgements}

445 We are grateful to our Veterans for their contributions to MVP. Full acknowledgements for the 446 VA Million Veteran Program COVID-19 Science Initiative can be found in the supplementary 
medRxiv preprint doi: https://doi.org/10.1101/2021.05.18.21257396; this version posted October 15, 2021. The copyright holder for this preprint (which was not certified by peer review) is the author/funder, who has granted medRxiv a license to display the preprint in perpetuity.

It is made available under a CC-BY 4.0 International license .

447

448

449

450

451

452

453

454

455

456

457

458

459

460

461

462

463

464

465

466

467

468

469

470

471

472

473

474

475

476

477

methods. We would like to thank the Host Genetic Initiative for making their data publicly

available (https://www.covid19hg.org/acknowledgements/).

\section{References}

1. CDC. About COVID-19 - CDC. : https://www.cdc.gov/coronavirus/2019ncov/cdcresponse/about-COVID-19.html

2. Dong E, Du H, Gardner L. An interactive web-based dashboard to track COVID-19 in real time. Lancet Infect Dis. 2020;20(5):533-534. doi:10.1016/S1473-3099(20)30120-1

3. The COVID-19 Host Genetics Initiative, ganna andrea. Mapping the Human Genetic Architecture of COVID-19 by Worldwide Meta-Analysis. Genetic and Genomic Medicine; 2021. doi:10.1101/2021.03.10.21252820

4. The GenOMICC Investigators, The ISARIC4C Investigators, The COVID-19 Human Genetics Initiative, et al. Genetic mechanisms of critical illness in COVID-19. Nature. 2021;591(7848):92-98. doi:10.1038/s41586-020-03065-y

5. Denny JC, Ritchie MD, Basford MA, et al. PheWAS: demonstrating the feasibility of a phenome-wide scan to discover gene-disease associations. Bioinformatics. 2010;26(9):1205-1210. doi:10.1093/bioinformatics/btq126

6. Gaziano JM, Concato J, Brophy M, et al. Million Veteran Program: A mega-biobank to study genetic influences on health and disease. J Clin Epidemiol. 2016;70:214-223. doi:10.1016/j.jclinepi.2015.09.016

7. Hunter-Zinck H, Shi Y, Li M, et al. Genotyping Array Design and Data Quality Control in the Million Veteran Program. Am J Hum Genet. 2020;106(4):535-548. doi:10.1016/j.ajhg.2020.03.004

8. 1000 Genomes Project Consortium, Auton A, Brooks LD, et al. A global reference for human genetic variation. Nature. 2015;526(7571):68-74. doi:10.1038/nature15393

9. Carroll RJ, Bastarache L, Denny JC. R PheWAS: data analysis and plotting tools for phenome-wide association studies in the R environment. Bioinformatics. 2014;30(16):23752376. doi:10.1093/bioinformatics/btu197

10. Verma A, Bradford Y, Dudek $S$, et al. A simulation study investigating power estimates in phenome-wide association studies. BMC Bioinformatics. 2018;19(1):120.

doi:10.1186/s12859-018-2135-0 
medRxiv preprint doi: https://doi.org/10.1101/2021.05.18.21257396; this version posted October 15, 2021. The copyright holder for this preprint (which was not certified by peer review) is the author/funder, who has granted medRxiv a license to display the preprint in perpetuity.

It is made available under a CC-BY 4.0 International license.

11. Fang H, Hui Q, Lynch J, et al. Harmonizing Genetic Ancestry and Self-identified Race/Ethnicity in Genome-wide Association Studies. Am J Hum Genet. 2019;105(4):763772. doi:10.1016/j.ajhg.2019.08.012

12. Allen RJ, Guillen-Guio B, Oldham JM, et al. Genome-Wide Association Study of Susceptibility to Idiopathic Pulmonary Fibrosis. Am J Respir Crit Care Med. 2020;201(5):564-574. doi:10.1164/rccm.201905-1017OC

13. Diogo D, Bastarache L, Liao KP, et al. TYK2 Protein-Coding Variants Protect against Rheumatoid Arthritis and Autoimmunity, with No Evidence of Major Pleiotropic Effects on Non-Autoimmune Complex Traits. Chiorini JA, ed. PLOS ONE. 2015;10(4):e0122271. doi:10.1371/journal.pone.0122271

14. Dendrou CA, Cortes A, Shipman L, et al. Resolving TYK2 locus genotype-to-phenotype differences in autoimmunity. Sci Transl Med. 2016;8(363):363ra149-363ra149. doi:10.1126/scitranslmed.aag1974

15. Hoiland RL, Fergusson NA, Mitra AR, et al. The association of ABO blood group with indices of disease severity and multiorgan dysfunction in COVID-19. Blood Adv. 2020;4(20):4981-4989. doi:10.1182/bloodadvances.2020002623

16. Zietz M, Zucker J, Tatonetti NP. Associations between blood type and COVID-19 infection, intubation, and death. Nat Commun. 2020;11(1):5761. doi:10.1038/s41467-02019623-x

17. Paranjpe I, Fuster V, Lala A, et al. Association of Treatment Dose Anticoagulation With InHospital Survival Among Hospitalized Patients With COVID-19. J Am Coll Cardiol. 2020;76(1):122-124. doi:10.1016/j.jacc.2020.05.001

18. Wu Z, McGoogan JM. Characteristics of and Important Lessons From the Coronavirus Disease 2019 (COVID-19) Outbreak in China: Summary of a Report of 72314 Cases From the Chinese Center for Disease Control and Prevention. JAMA. Published online February 24, 2020. doi:10.1001/jama.2020.2648

19. Matsunaga H, Ito K, Akiyama M, et al. Transethnic Meta-Analysis of Genome-Wide Association Studies Identifies Three New Loci and Characterizes Population-Specific Differences for Coronary Artery Disease. Circ Genomic Precis Med. 2020;13(3):e002670. doi:10.1161/CIRCGEN.119.002670

20. Plagnol V, Howson JMM, Smyth DJ, et al. Genome-wide association analysis of autoantibody positivity in type 1 diabetes cases. PLoS Genet. 2011;7(8):e1002216. doi:10.1371/journal.pgen.1002216

21. Reilly MP, Li M, He J, et al. Identification of ADAMTS7 as a novel locus for coronary atherosclerosis and association of $\mathrm{ABO}$ with myocardial infarction in the presence of coronary atherosclerosis: two genome-wide association studies. Lancet Lond Engl. 2011;377(9763):383-392. doi:10.1016/S0140-6736(10)61996-4 
medRxiv preprint doi: https://doi.org/10.1101/2021.05.18.21257396; this version posted October 15, 2021. The copyright holder for this preprint (which was not certified by peer review) is the author/funder, who has granted medRxiv a license to display the preprint in perpetuity.

It is made available under a CC-BY 4.0 International license.

22. Trégouët D-A, Heath S, Saut N, et al. Common susceptibility alleles are unlikely to contribute as strongly as the FV and $\mathrm{ABO}$ loci to VTE risk: results from a GWAS approach. Blood. 2009;113(21):5298-5303. doi:10.1182/blood-2008-11-190389

23. Larson NB, Bell EJ, Decker PA, et al. ABO blood group associations with markers of endothelial dysfunction in the Multi-Ethnic Study of Atherosclerosis. Atherosclerosis. 2016;251:422-429. doi:10.1016/j.atherosclerosis.2016.05.049

24. Gallay L, Uzunhan Y, Borie R, et al. Risk Factors for Mortality after COVID-19 in Patients with Preexisting Interstitial Lung Disease. Am J Respir Crit Care Med. 2021;203(2):245249. doi:10.1164/rccm.202007-2638LE

25. Verma A, Minnier J, Huffman JE, et al. A MUC5B Gene Polymorphism, Rs35705950-T, Confers Protective Effects in COVID-19 Infection. Infectious Diseases (except HIV/AIDS); 2021. doi:10.1101/2021.09.28.21263911

26. Kim WJ, Sheen SS, Kim T-H, et al. Association between CRHRI polymorphism and improved lung function in response to inhaled corticosteroid in patients with COPD. Respirology. 2009;14(2):260-263. doi:10.1111/j.1440-1843.2008.01425.x

27. The RECOVERY Collaborative Group. Dexamethasone in Hospitalized Patients with Covid-19. N Engl J Med. 2021;384(8):693-704. doi:10.1056/NEJMoa2021436

28. Nemoto M, Hattori $\mathrm{H}$, Maeda N, et al. Compound heterozygous TYK2 mutations underlie primary immunodeficiency with T-cell lymphopenia. Sci Rep. 2018;8(1):6956. doi:10.1038/s41598-018-25260-8

29. Hellquist A, Järvinen TM, Koskenmies S, et al. Evidence for Genetic Association and Interaction Between the TYK2 and IRF5 Genes in Systemic Lupus Erythematosus. $J$ Rheumatol. 2009;36(8):1631-1638. doi:10.3899/jrheum.081160

30. Sigurdsson S, Nordmark G, Göring HHH, et al. Polymorphisms in the Tyrosine Kinase 2 and Interferon Regulatory Factor 5 Genes Are Associated with Systemic Lupus Erythematosus. Am J Hum Genet. 2005;76(3):528-537. doi:10.1086/428480

31. The Wellcome Trust Case-Control Consortium (WTCCC) and Alastair Compston, Ban M, Goris A, et al. Replication analysis identifies TYK2 as a multiple sclerosis susceptibility factor. Eur J Hum Genet. 2009;17(10):1309-1313. doi:10.1038/ejhg.2009.41

32. Cunninghame Graham DS, Morris DL, Bhangale TR, et al. Association of NCF2, IKZF1, IRF8, IFIH1, and TYK2 with Systemic Lupus Erythematosus. McCarthy MI, ed. PLoS Genet. 2011;7(10):e1002341. doi:10.1371/journal.pgen.1002341

33. Watford WT, O'Shea JJ. Human Tyk2 Kinase Deficiency: Another Primary Immunodeficiency Syndrome. Immunity. 2006;25(5):695-697. doi:10.1016/j.immuni.2006.10.007 
medRxiv preprint doi: https://doi.org/10.1101/2021.05.18.21257396; this version posted October 15, 2021. The copyright holder for this preprint (which was not certified by peer review) is the author/funder, who has granted medRxiv a license to display the preprint in perpetuity.

It is made available under a CC-BY 4.0 International license.

34. Tantisira KG, Lake S, Silverman ES, et al. Corticosteroid pharmacogenetics: association of sequence variants in CRHR1 with improved lung function in asthmatics treated with inhaled corticosteroids. Hum Mol Genet. 2004;13(13):1353-1359. doi:10.1093/hmg/ddh149

35. Boxer L, Dale DC. Neutropenia: Causes and consequences. Semin Hematol. 2002;39(2):75-

36. Reich D, Nalls MA, Kao WHL, et al. Reduced Neutrophil Count in People of African Descent Is Due To a Regulatory Variant in the Duffy Antigen Receptor for Chemokines Gene. Visscher PM, ed. PLoS Genet. 2009;5(1):e1000360. doi:10.1371/journal.pgen.1000360

Table 1. Patient characteristics of Million Veteran Program participants

\begin{tabular}{|r|c|}
\hline \multicolumn{1}{|c|}{ Characteristics } & Million Veteran Program \\
\hline Total Patients & Number (\%) \\
\cline { 2 - 3 } Male & 658,582 \\
\hline Genetic Ancestry & $592,516(90)$ \\
\hline \multicolumn{1}{|c|}{ European } & \\
\hline African & $464,961(70)$ \\
\hline Hispanic & $123,120(19)$ \\
\hline Asian & $52,183(8)$ \\
\hline Other & $83,29(1)$ \\
\hline Oomorbidities & $99,89(2)$ \\
\hline Type 2 Diabetes (phecode $=250.2)$ & $283,197(43)$ \\
\hline Coronary Artery Disease (phecode $=411.4)$ & $451,998(69)$ \\
\hline Chronic Kidney Disease (phecode $=585.2)$ & $227,575(34)$ \\
\hline
\end{tabular}


567 Table 2. Phenotypes sharing association with variants also associated with severe COVID-19 568 infection, with reduced odds of disease listed in order of $p$-value*.

569

570

571

572

573

574

575

576

577

578

579

580

581

\begin{tabular}{|c|c|c|c|c|c|}
\hline Phenotype & OR $(95 \% \mathrm{Cl})$ & $p$-value & Gene & SNP & $\begin{array}{l}\text { COVID- } \\
\text { severity }\end{array}$ \\
\hline Psoriasis & $0.89[0.86-0.91]$ & $6.48 \mathrm{E}-23$ & TYK2 & rs11085727 & Both \\
\hline Rosacea & $0.84[0.8-0.89]$ & $7.54 \mathrm{E}-16$ & HLA-DPB1 & rs9501257 & Critical \\
\hline Psoriatic arthropathy & $0.82[0.77-0.88]$ & $6.97 \mathrm{E}-12$ & TYK2 & rs11085727 & Both \\
\hline Post-inflammatory pulmonary fibrosis & $0.87[0.83-0.92]$ & $4.54 \mathrm{E}-09$ & NSF & rs9896243 & Critical \\
\hline Vitiligo & $0.69[0.56-0.82]$ & $3.03 \mathrm{E}-08$ & CCHCR1 & rs111837807 & Both \\
\hline Sarcoidosis & $0.74[0.62-0.85]$ & $1.80 \mathrm{E}-07$ & CCHCR1 & rs111837807 & Both \\
\hline Lupus (localized and systemic) & $0.84[0.77-0.91]$ & $3.97 \mathrm{E}-06$ & TYK2 & rs11085727 & Both \\
\hline Cutaneous lupus erythematosus & $0.79[0.68-0.89]$ & $6.21 \mathrm{E}-06$ & TYK2 & rs11085727 & Both \\
\hline Post-inflammatory pulmonary fibrosis & $0.85[0.8-0.9]$ & $2.26 \mathrm{E}-12$ & CRHR1 & rs61667602 & Hospitalized \\
\hline Rheumatoid arthritis & $0.84[0.79-0.9]$ & $4.20 \mathrm{E}-10$ & HLA-DRA & rs9268576 & Hospitalized \\
\hline Idiopathic fibrosing alveolitis & $0.81[0.73-0.88]$ & $1.58 \mathrm{E}-08$ & CRHR1 & rs61667602 & Hospitalized \\
\hline $\begin{array}{l}\text { Rheumatoid arthritis and other inflammatory } \\
\text { polyarthropathies }\end{array}$ & $0.88[0.84-0.93]$ & $6.34 \mathrm{E}-08$ & $H L A-D R A$ & rs9268576 & Hospitalized \\
\hline $\begin{array}{l}\text { Other alveolar and parietoalveolar } \\
\text { pneumonopathy }\end{array}$ & $0.88[0.83-0.93]$ & $7.50 \mathrm{E}-07$ & CRHR1 & rs61667602 & Hospitalized \\
\hline
\end{tabular}

*OR<0.9 and $\mathrm{P}<10-5$ shown in table, full results in supplementary; if multiple related conditions, e.g. psoriasis, psoriasis vulgaris, psoriasis and related disorders, description with lowest p-value selected shown in table.

Fig 1. Overview of variant selection and PheWAS analysis design.

Fig 2. PheWAS results of candidate SNPs from GWAS of critically ill and hospitalized COVID-

19. Significant associations between 48 SNPs from critical ill COVID GWAS (A) and 39 SNPs

from hospitalized COVID (C) and EHR derived phenotypes in the Million Veteran Program. The

phenotypes are represented on the x-axis and ordered by broader disease categories. The red line

denotes the significance threshold using false discovery rate of $1 \%$ using the Benjamini-

Hochberg procedure. The description of phenotypes is highlighted for the associations with FDR

$<0.1$ and odds ratio $<0.90$ or odds ratio $>1.10$ B) and D) A heatmap plot of SNPs with at least

one significant association $(\mathrm{FDR}<0.1)$. The direction of effect disease risk is represented by 
medRxiv preprint doi: https://doi.org/10.1101/2021.05.18.21257396; this version posted October 15, 2021. The copyright holder for this preprint (which was not certified by peer review) is the author/funder, who has granted medRxiv a license to display the preprint in perpetuity.

It is made available under a CC-BY 4.0 International license.

582 odds ratio. A red color indicates increased risk and blue color indicated reduced risk. The results

583 with odds ratio $<0.90$ or odds ratio $>1.10$ are shown.

584 Fig 3. PheWAS results of candidate SNPs from GWAS of Hospitalized COVID-19 in AFR

585 ancestry individuals. The plot highlights the association between rs581342 SNP and

586 Neutropenia, which was only observed in the AFR ancestry. The phenotypes are represented on

587 the $\mathrm{x}$-axis and ordered by broader disease categories. The red line denotes the significance

588 threshold using false discovery rate of $1 \%$ using the Benjamini-Hochberg procedure. The table

589 on the top right of the plot shows the association results between rs581342 and neutropenia in

590 other ancestries. The association was not tested among participants of ASN ancestry due to low

591 case numbers. 
GWAS summary statistics (Freeze 6) analyzed for PheWAS:

- COVID-19 critically ill vs Population (A2)

- COVID-19 hospitalized vs Population (B2)
* SNPs were clumped and pruned using the $1000 \mathrm{G}$ reference panel

* FDR $=0.01$

- $R^{2}$ threshold $=0.1$

* Distance threshold = $250 \mathrm{~kb}$

* 35 lead loci were identified from critically ill COVID-19 vs population GWAS

* 42 lead loci identified from hospitalized COVID-19 vs population GWAS

\section{Genotype Data}

* 1000G imputed data

* Ancestry defined by HARE algorithm

- Total N=658,582

* EUR $=464,961$

* AFR $=123,120$

- Hispanic = 52,183

* Asian = 8,329

\section{Phenotype Data}

* ICD-9/10 codes mapped to phecodes

* Case-Control Definition:

* Cases: >=2 phecodes

* Controls: No phecodes

* Phecodes with cases $<200$ were dropped

* Total phecodes : 1,688
* Ancestry specific PheWAS * Logistic or firth regression * Covariates
* 1st 20 PCs
* Sex
* Age
* Age $^{2}$

* Transethnic Meta-analysis 


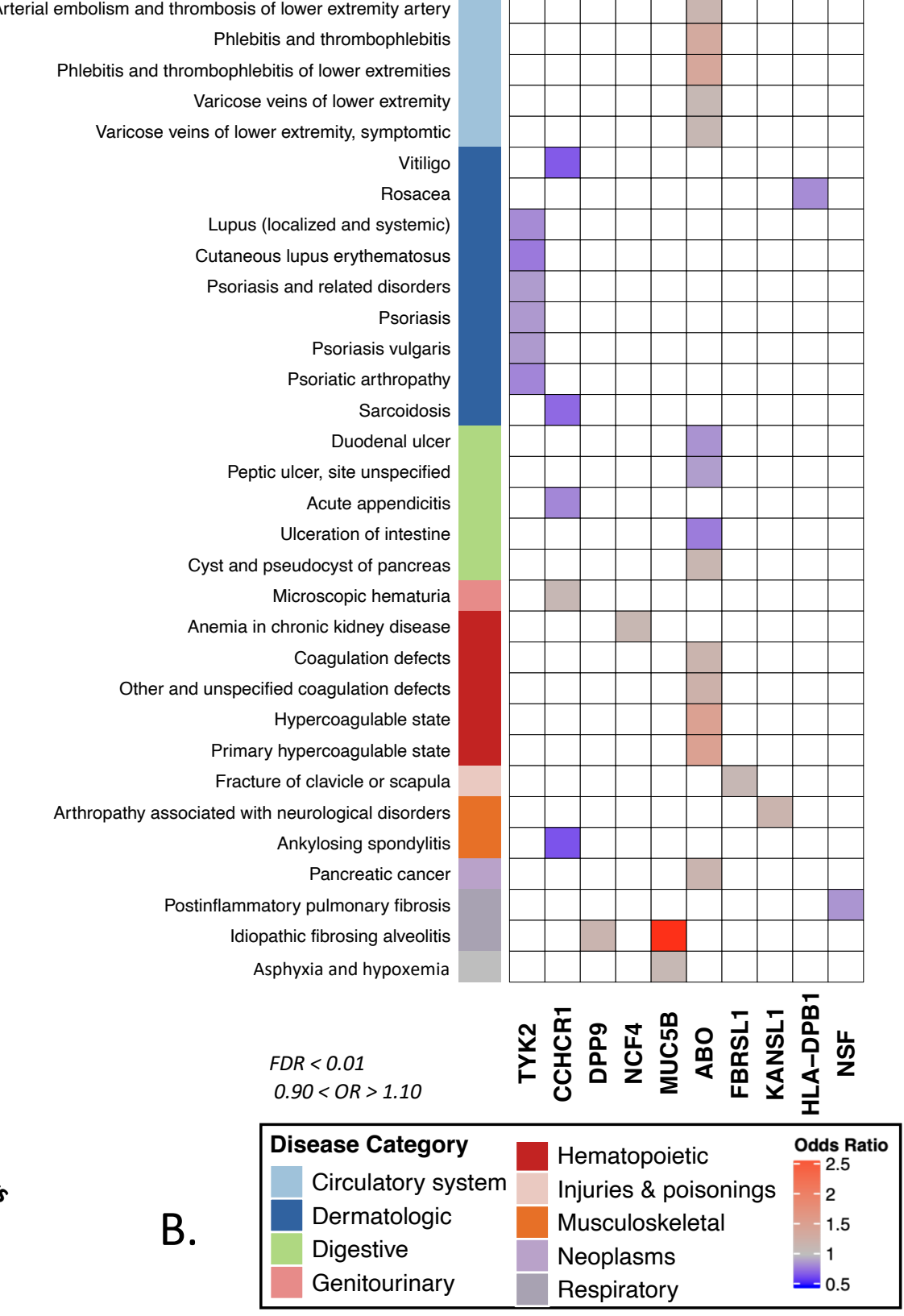

A.

Phlebitis and thrombophlebitis of lower extremities

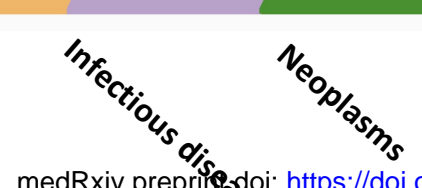

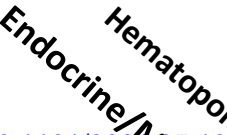
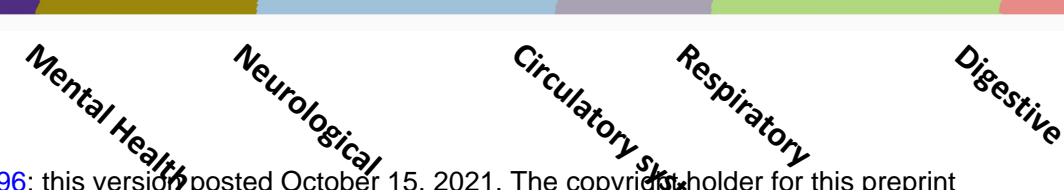

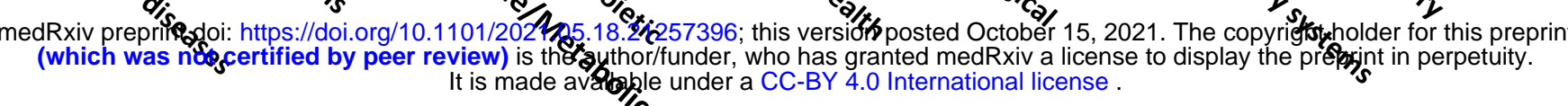

Direction of effect $\triangle$ Risk $\nabla$ Protective

Other venous embolism and thrombosis

Phlebitis and thrombophlebitis of lower extremities

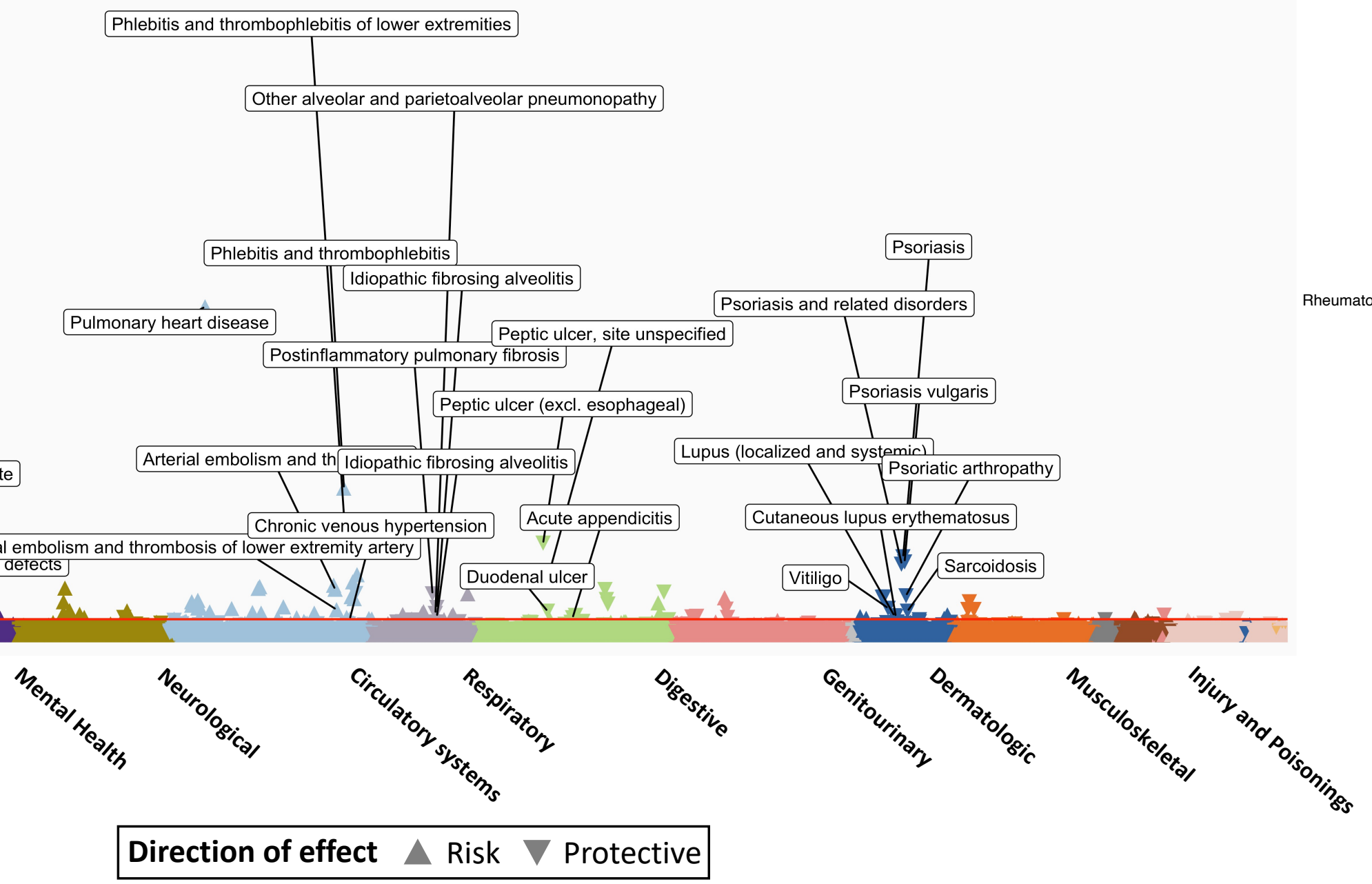




\begin{tabular}{|c|c|c|c|c|}
\hline Ancestry & MAF & OR & P & Cases/Controls \\
\hline AFR & 0.56 & 1.29 & $3.1 \times 10^{-13}$ & $1,788 / 113,277$ \\
\hline EUR & 0.07 & 1.05 & 0.24 & $3,855 / 438,702$ \\
\hline HIS & 0.10 & 1.65 & $8.84 \times 10^{-06}$ & $308 / 49,162$ \\
\hline
\end{tabular}

30

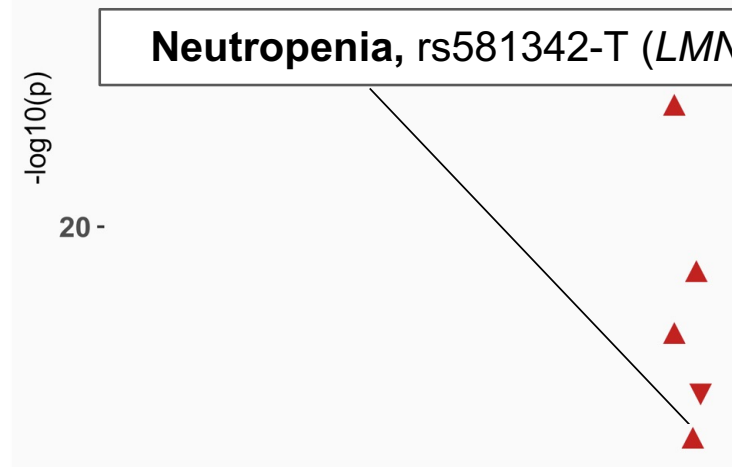

10

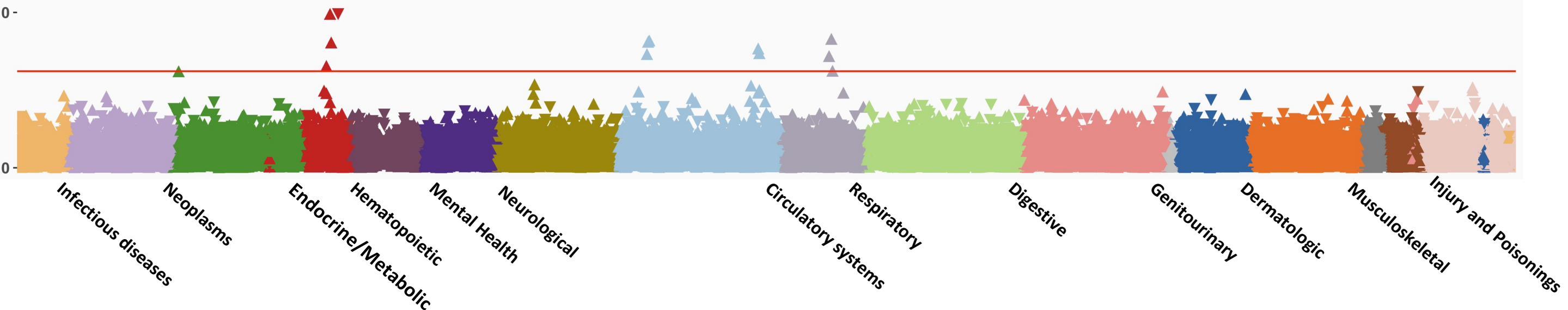

